Photographs were used to show the residual toxicity of the above materials to $A$. pomi when applied in aqueous solution to the leaves of apple seedlings.

Virus diseases of tree fruits. Little is known of the actual extent of virus diseases of fruit trees in Britain, but virus-like symptoms are commonly seen in orchards; a number of specimens showing leaf symptoms probably caused by virus infection were shown, including mosaics, ring-spots, linepatterns, and necrotic spots. In addition to leaf symptoms, virus infection can cause changes in growth habit; this type of symptom was illustrated by rubbery wood of apple and stunt of plum. In rubbery apple, lignification of the wood is irregular and delayed, with the result that the young branches are flexible and soft and the tree has a 'weeping' habit of growth ; in stunted plum the wood in the shoots is very poorly developed, while the tissues outside the wood are thick and spongy, and as a result the shoots are very brittle. In both diseases the inter. nodes are shortened. Neither of these diseases causes leaf symptoms on the host on which they were first recorded, but plum stunt causes a faint mosaic on the cherry root-stock $F .12 / 1$, an example of which was shown.

G. T. SPINKS

\section{ELECTRONIC INSTRUMENTS AND DEVICES}

$\mathrm{A}^{\mathrm{T}}$

$T$ first sight, the exhibition of the Institution of - Electronics (N.W. Branch), held at Manchester during July 19-21, was perhaps a little disappointing after last year's brilliant display ; but a closer inspection revealed that, although there were fewer spectacular demonstrations, a remarkable number of new, ingenious and useful devices were on show. Since it is obviously impossible to mention them all in the space allowed, a few of the most novel and interesting exhibits will be described.

An outstanding feature of the exhibition was the substitution of television demonstrations for the usual film shows. The receivers used were all built by members of the Institution, either from a commercial kit of parts or from government surplus equipment, and a short lantern lecture on the elementary principles of television preceded each demonstration.

Among the high-vacuum equipment displayed by British American Research, Ltd., was a new type of gauge known as the 'Alphatron', which has a linear response from 1 micron to $10 \mathrm{~mm}$. of mercury. It is an ionization gauge in which a small quantity of radium provides a constant source of alpha-particles as the ionizing agent, and is consequently more robust and stable than the conventional type which uses electrons emitted from a heated filament.

Dawe Instruments, Ltd., displayed a stroboscope specially designed for viewing the moving shuttle of a textile loom. It uses an extremely high-intensity flash which gives a clear view of a moving object at very low repetition-rates, and a remote phase-control enables the operator to view the shuttle at any position during its traverse. The same firm also demonstrated its sound-level meter, which has been completely redesigned and now, while retaining the features of the earlier model, has its size and weight reduced by approximately one-half.

A high-voltage insulation tester which gives aural warning of the approach of a breakdown was dis- played by the English Electric Co., Ltd. A continuously variable D.C. potential of up to $10 \mathrm{kV}$. is derived by rectification of the output of an air-cored transformer which is fed by a high-frequency valve oscillator. The A.c. components of the ionization current which precedes breakdown are amplified and fed to a small loudspeaker. The instrument is portable and, since the maximum current obtainable is $0.5 \mathrm{~mA}$., it is completely safe. Among other equipment demonstrated by this firm were a $5-\mathrm{kW}$. induction heater designed as a general production tool rather than for specialized work, and a stepless controller for $\frac{1}{2}$ h.p. D.c. motors using a magnetic amplifier and metal rectifiers.

Interesting demonstrations of the phenomenon of electron diffraction were provided by Ferranti, Ltd. Cathode ray tubes are used in which a specimen of crystalline material is supported in the beam and the diffraction pattern observed on the screen. This firm also has available a continuously pumped tube in which specimens can be changed at will.

The equipment displayed and demonstrated by Fielden (Electronics), Ltd., was an excellent example of the way in which one or two basic instruments can be made to serve a large number of specialized purposes. In particular, the proximity meter, displayed in its basic form at last year's exhibition, and which depends on the measurement of very small capacity changes, has been made the basis of a bewildering variety of new instruments. Perhaps the most interesting application is in a new type of recorder which has the sensitivity of a high-grade pointer galvanometer but sufficient power to operate a substantial pen. A servo mechanism combined with the proximity device causes the pen to follow the pointer by maintaining a constant capacity between light vanes fixed to each. There is thus no mechanical contact between the meter and the recording mechanism. A similar principle is involved in an instrument for recording changes in level of a liquid as in a manometer or thermometer. Other applications which were illustrated involved counters, tolerance gauges, moisture indicators and a recording hygrometer.

A new standard 'signal generator by Marconi Instruments, Ltd., provides a continuously variable output from 0.4 micro-volts to 4 volts in the frequency range $15 \mathrm{kc} . / \mathrm{s} .-30 \mathrm{Mc} . / \mathrm{s}$. Several unusual features are incorporated: a crystal-controlled oscillator for calibration checking and a novel form of concentric terminating unit are of special interest. The latter provides three output conditions-source impedances of $75 \mathrm{ohms}$ and $30 \mathrm{ohms}$ and a dummy aerial-and the fundamental circuit of each is indicated by a line diagram which changes as the switch is changed.

Metropolitan-Vickers Electrical Co., Ltd., displayed the precision wave-guide test gear for the $3-\mathrm{cm}$. band which has been developed in conjunction with the Telecommunications Research Establishment of the Ministry of Supply. Its own centimetre-wave signal source, which is of extremely small dimensions, was also on show. The latter provides a signal, tunable between 8,500 and $9,700 \mathrm{Mc}$./s., from a $723 \mathrm{~A} / B$ reflex klystron with a built-in wavemeter and attenuator.

The new audio-frequency wave analyser displayed by Muirhead and Co., Ltd., has been produced in collaboration with the Pametrada Research Station, Wallsend. It is designed primarily to assist the investigation of noise and vibration in marine tur- 
bines, and operates in the frequency range 19-21,000 cycles. The weight and size of the equipment have been minimized by the use of resistance-capacitance circuits in place of the usual inductance-capacitance type which, at these frequencies, would require very large iron-cored chokes. The analyser has two selective amplifiers in series which may be exactly in tune, 3 per cent apart or 10 per cent apart, to provide three different band-widths.

A number of new valves which, hitherto, have not been manufactured in Great Britain were displayed by Mullard Electronic Products, Ltd. Of special interest were a $3-\mathrm{cm}$. band reflex klystron with an output of $25 \mathrm{~mW}$., and two new thyratrons, one containing xenon and the other hydrogen. These should prove useful to workers who have been relying on supplies of American surplus equipment.

F. C. Robinson and Partners, Ltd., demonstrated the 'beta' thickness gauge made by the Baldwin Instrument Co., Ltd. A radioactive isotope emits $\beta$-rays which fall on an ionization chamber. Any material placed between the two will absorb part of related to the thickness of the sheet. The instrument is normally calibrated to read mass per unit area; but if a material of constant density is used it can be made to read thickness directly. Also on view at this stand was the Scophony-Baird home tape recorder, which gives remarkably high-quality record. ings lasting half an hour on a 1,200-ft. reel of plastic tape impregnated with iron dust.

In conclusion, perhaps a word of congratulation to the exhibitors in general might be allowed on the extremely attractive, though modest, appearance of all the displays.

c. A. TAYLOR the radiation, and the change in ionization can be

of its members very great technical resources, it is natural that the Association itself should tend to pursue "longer term, more fundamental and background research".

The subject of electrical engineering materials stands very high in the list of the Association's activities. Important fundamental work on dielectrics has been carried on both in the Association's laboratories and on an 'extra-mural' basis in several university departments and at the National Physical Laboratory. Research on magnetic materials, directed towards the improvement of the quality of electrical sheet-steels and to the production of improved permanent-magnet materials, has, for the most part, been supported in university laboratories. Electrical discharge phenomena have been the subject of extensive research both in relation to problems of direct practical interest in connexion with circuit. breaking and also in the fundamental field. The application of the theory of the electrical discharge, which was developed by Mr. C. E. R. Bruce to certain astrophysical problems, has been further extended by him.

Among the numerous researches on very varied topics listed in the report may be mentioned: the use of wind-power for generation, further work on communication interference and radio interference, short-circuit stresses in transformers and parasitic forces in integrating electricity meters. A totel of ninety reports was issued during the year. In a paragraph dealing with organisation and staff, an interesting comment is made on the incidental function which the Association performs in training young scientific staff for the electrical industry.

\section{UNIVERSITIES AND MANAGEMENT}

\section{BRITISH ELECTRICAL AND ALLIED INDUSTRIES RESEARCH ASSOCIATION}

\section{ANNUAL REPORT FOR 1948-49}

$\mathrm{T}$ HE work of the British Electrical and Allied Industries Research Association for the year ended September 30, 1949, is reviewed in the twenty-ninth annual report, issued recently*.

The Association has long played a part in the scientific and technical development of the electricity supply industry, and this has been recognized by the British Electricity Authority by the adherence as ordinary members of the Association of the Central Authority and of the Area Boards. In reviewing the general struature of the Association, which is based on twenty-three sectional committees, stress is laid on the useful scientific liaison which the Association effects. These committees, which have a primary responsibility for advising on research policy in their respective fields, form a meeting ground for research workers from industry, government establishments and from the universities, and their influence is, in consequence, a good deal wider than might be inferred from their immediate responsibilities to the Association. It is pointed out that, as the Association serves an industry which has within the organisations

* British Electrical and Allied Industries Research Association. Twenty-ninth Annual Report, October 1,1948 , to September 30, 1949. Pp. 188. (Leatherhead.
$\mathrm{N}$ the concluding address to the British Institute I of Management conference at Harrogate in November 1949, Lord Lindsay stated that we are living in an age of technological revolution and that the productivity of a modern nation depends upon science and perhaps even more so is connected with is meant not just what is taught and produced in the natural science faculties but that taught and produced in any proper university environment. It is a restless inquiring spirit, and the economic success of a modern industrial nation depends upon how far that spirit is pushed right down through the whole of society. To achieve the things Great Britain requires will depend upon two factors, the first being the extent to which this spirit of scientific research goes; it should not be confined to people in the universities but sent right down to the men at the bench. The second is how far each individual has public concern, that is, concern with how the country is run, understanding of the common man and those items needed in the structure of society.

The responsibility of the university in relation to the job would therefore seem to be to produce the science and skill necessary for our modern economic situation-more especially to introduce the scientific spirit, thought and outlook-and to give everybody a sense of citizenship. This means that university training must not be purely specialized although it must have a specialist or technical side. "An arts degree tends to produce an awful lot of uplift and makes people somewhat impractical and out of touch a spirit of scientific research. By scientific research 